\title{
WRIT Y ACTIO EN EL SURGIMIENTO Y CONFORMACIÓN DEL PROCESO CIVIL
}

\section{INGLÉS MEDIEVALC)}

\author{
Avmao 1. Penez Ragone \\ Docter en Derechu urt la Chiversidsd de Coionia.

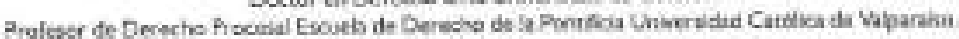

\section{Sumatio:}

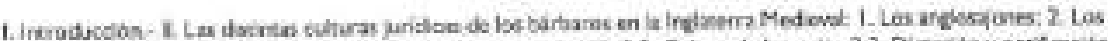

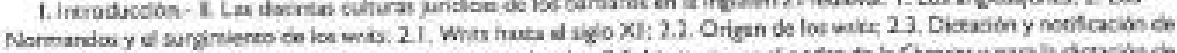

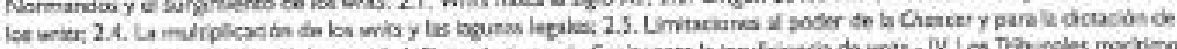

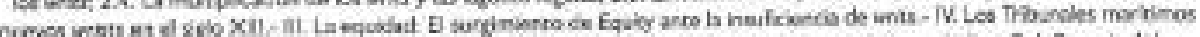

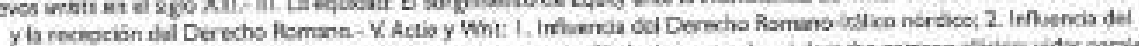

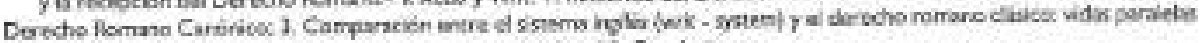
y no derivadas. Vi. Condwores.

\section{INTRODUCCIÓN}

El nuevo proceso clvilingles de 1998 como cuerpo sistematizado de normas similar a un código constiturye sin dudz un importante hito que rompo con una tradición de más de 1000 ahos. La distinción entre derecho material y procesal ers impensable hasta un siglo acris. La conformación de las bases del proceso chil inglés en el medioevo dio lugar a ua estema ínico donde el punto de partida era la posibilidad de turela de un derecho invocado como presupuesto para su existencia misma. ' $\mathrm{L}$ irtsuaridad inglesa sin duda coadyuvó a que el sistema que surgí́ an el medioevo terga notas particulares propias, pero al mismo tiempo comunes y conectadas a otros sisternas juridicos existentes.?

La conexión del "derochio" (righte) con la "acción" (writ) dio un carácter particular al procesal medieval ingles. Bien puede decirse que existió un sistema juridico ordenado ent base al ressuardo jurisdiccional de los derechos.' Cuando se refiere a este, se alude a una concepción del derecho, on la cual la fijación y determiración del derecho marenal deviene de la posiblidad de su resguardo efectivo mediante determinados procedimientos y órganos predispuestos. El derecho en su conjunto es perisado a partir del derecho procesal no sicndo escindible ni perisable el derecho que se aloga vulnerado del proceso en el cual se hace valer. Puede asi ser designado come un sistema juridico por acciones. 'Califcarivo que cabe tambien al Derecho Rorrano clasico. En afecto los elementcs comunes encre la "actio" y d" "writ" son notables. El procesocivil inglés del periodo medievá temprano y medio se presenta como un respetablo erisol juridice espejo del sistema de acciones del derecho remano, con una decisiva impronta de les diferentes paebles bárbaros y con cierta influencia del derecho romano-canórico."

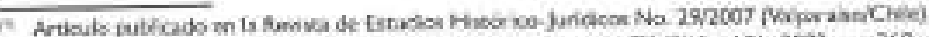

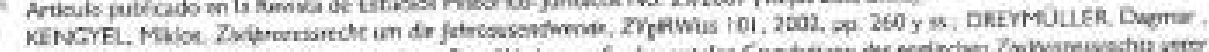

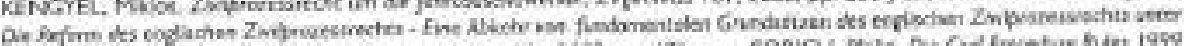

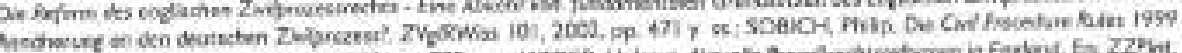

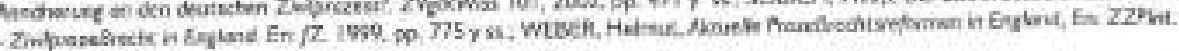
$2000, p \rho 59$ y $\mathrm{m}$

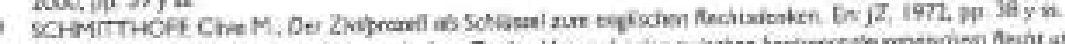

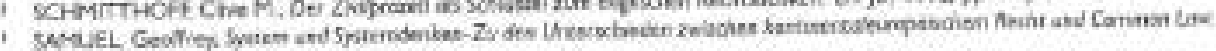
7EA 3 . 1975. pp. 375 y ss

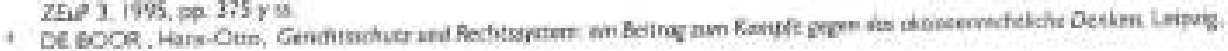
IWit, 2.20

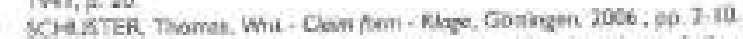

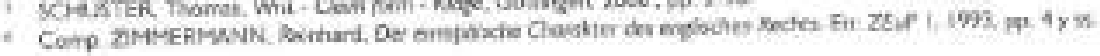


Las simalitudes y cercaniss del Derecho Romana Privado y su sistema de acciones con la coniormación del sssterra medieval ingiés podriar hacer augerir "recepción" o "infivencia directa". Sin embargo no resulta acertado confundir "influencia" y "similitudes" con "recepciön". La metodólogía que empleari este trabajo sonsistiri en exponer los puntos de contacto como "vidas paralelas" en tarto aspectos de concordancia y de divergenca.' Para allo será menester primero abordar of surgimionto de los writs en $\alpha$ proceso medieval inglés. Luego se analizara la influencia que ejercieron les derachos germano, anglosajón. normando y france. Finamente se desarrollarán las hipótesis de influancia del derecho romano, del derecho romano-italiano y firalmente del romano canónico.

Sostener sin más la influencia inmediata del derecho romano clásico sobre el proceso óvil inglés medieval no es una afirmación valiida en términcs absolutos." Los argumentos tradicionales fundados en la obra de Oscar Olguín Silos y la influencis normanda, romano-itálica o romanocanónica como puentes para ta influencia romana sumados a la similitud de la octio con el writ no resultan argumentos suficientes.' En primer lugar se tratará de justificar la tesis dol surgimiento original del proceso civil inglés medieval con la determinante influencia del derecho de los distintos pueblos tárbaros y solo apenas residual del proceso civil romano." Asi tampoco es dabie sostoner que, mediante is influencia def derecho arglosajón, normando o franco se haya verificado una recepción medaca del siscema formulario romano, En segundo lugar, también se tratará la influencla del proceso romano-itálico (en especial del procedimiento longobardo)!." Con la llegada del jurista lombar do Vaccarius a Ingluterra en el afio 1143 -con vasto conocimiento del derocho romano, transmitiendo las cuatro partes de la codificación del Corpus juris-podrla haberse verificado por este via la influencia del proceso romano." Finalmonte se examinará la al ternativa de recepción mediata del processo remano-canónico pera la conflormación del sistema inglés medieval de fórmulas.

\section{LAS DISTINTAS CULTURAS JURIDICAS DE LOS BÁRBAROS EN LA INGLATERRA MEDIEVAL}

El formalismo procedimental anglosajón de origen germano tuvo cuatro importantes caracteristicas. ${ }^{13}$ En primer lugar estaba excesivamente sujeto al rito de modo tal que, la inobservancia de mirúsculas exigencias podia conducir al rechazo de la dernanda y con ello a la falca do tutela del derecho. En segundo lugar, el sisterna probatorio consecuente con el rigorismo formal se asentaba en pruebas tasadas. Subsidiariamence cuando las proebas producidas no ofrecian grado de comvencimiento se acudian a medios de prueba irracionales (vg. ordalias, duelos do Dios. etc.), pero que en definitiva aseguraban siernpre un resultado positivo o negativo sobre lo que se alegaba. Este sistema de prueba formul y no de mérito fundaba suficientemente la sentencia que

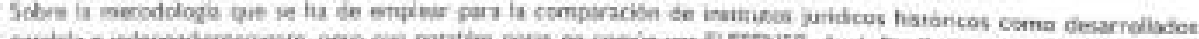

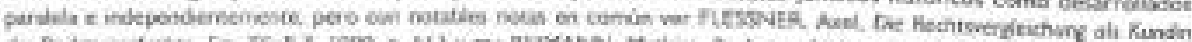

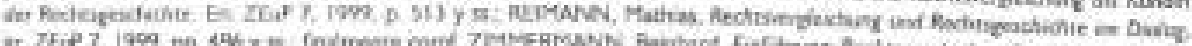

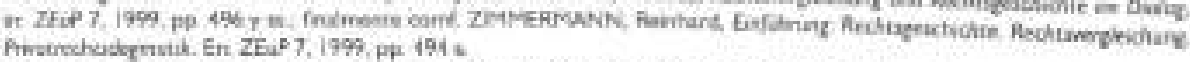

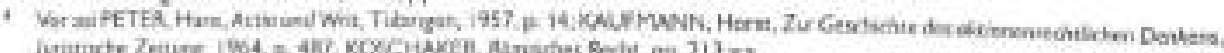

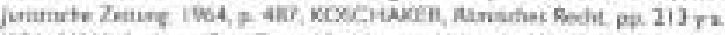

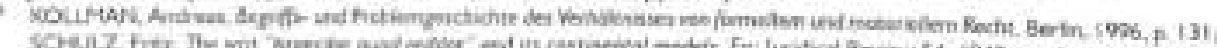

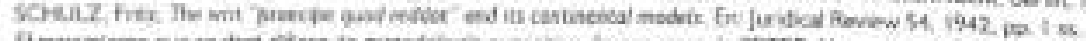

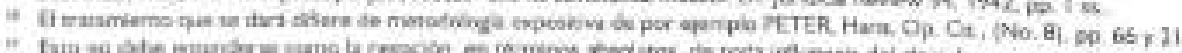

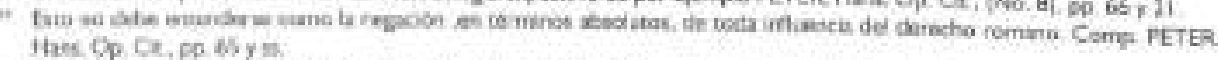

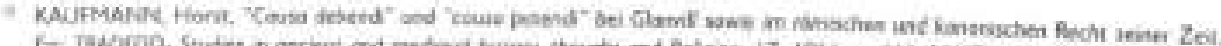

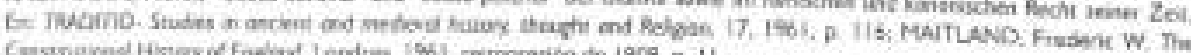

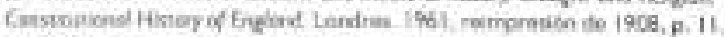

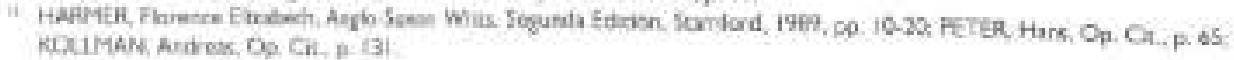


se dictaba. ${ }^{14}$ La certeza de la respuesta asentada en un Dios aseguraba siempre un resultado. En tercer lagar era costumbrista y sin formulación escrita no conociendo propiarnente un sisterna de acciones. " Finalmante el resabio germano impidia que se pudieran separar el hecho del derecho. La dernanda como la prucba rexclaban rito, hechos y derecho sin distinciòn alguna entre lo que se solicitaba y el porque se lo solicitaba. Todo ollo generó un sistema dondo de toda actividad probatoria necesariamente se derivaban consecuencias de acontecimientos con naturaleza irracional y sesgos religiosos, que daban certezs y retroalimentaban el respeto al ritualismo. 16 El sisterra era idealmente perfecto: abjetividad absoluta por dependencia de fenómenos no decerminables por el organo que asumía función jurigdiecional y efectividad en la respuesta que excluta toda lagula. En definitiva, todo era respuesta divina no siando el juez mis quo un mero agente $e$ instrumerito."

La conquisa normanda significó no solo una mayor institucionalización, racionalazación centralización y organización, sino además las bases para el surgimiento paufarino del Camman Low. " La necesidad de centralizar el control de todas las funciones en el rey llevob a la creación de víncules jerárquicos de simple y directo acceso a aque. ${ }^{19}$ Ne fue una encepeión la función judicial, Incluso en el periodo inicial las controversias juridicas con gran contenido polltico eran solucionadas en forma persorid por los reyes. Es a partir del sto I 100 que las cortes reales de primera instancia comienzan a conocer en los proceses bajo su competencia ${ }^{\text {ar }}$ Dos elementos resultan importantes en esta esapa normanda inicial. En primer lugar la formalidad preexistonte anglosajona comienza a recaptarse en fórmulas para hacer valar los derechos ante las coctes. En segundo lugar, el sisterna probatario formal, tasado y ritualistico anglosajón es sustituido por uno de mérito dande se daba lbertad al juez y no necesariamente debia sujetarse a fonómenos o datos predeterminados en la apreciación y valoración de sus consecuencias. "A lo largo de la segunda mitad del sigla XIl el juez real corgaba por ajemplo al demandado otro mecankmo probatario diference al duela, más racional con prueba y contrapruchn. Pero elio debia llewarse a cabo ance un grupo de vecinos. Asi se determinaba y se procedia a elegir un determinado número de vecinos los cuales eran citados a los efectos de responder preguntas vinciladas con la cuestión litigiosa. ${ }^{22}$ Este procodimiento difería del similar establecido en el derecho germano consistente en el juramento requerido a determinados vechos ctados por las propias partes. En el sistema normando era in funciorario audiar, el sheriff. cumplendo orden directa del mismo tribund quien procodia a su dección y citacion. Para importame parte de la doctrina este es el origen de los jurados. Esto asin cuando desde el punto de vista cromológico pueda presumirse que elilo se debic a la influencia del derecho romano-itálice en Inglaterra por los francos -en la figura denominada "priwlegs"- que fue recuptach en forma dirncta por les normandos. En efecto estos fueron fuertemente influenciados durante su ecupación de Normandis alrededor del año 900 por el derecho franco-carolingjo mediante is fgura denominada "inçumsitio" a los efectos de proteger las derechos de los reyes e invistièndolos de la posibilidad de actuación tanto parn dirección

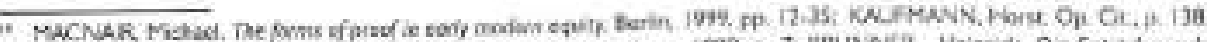

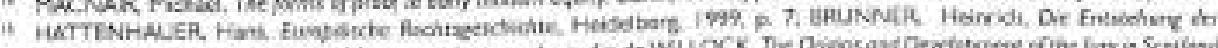

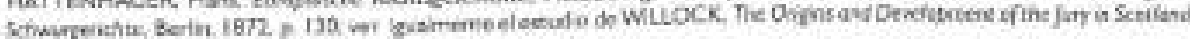
Ednturgo, 1 \&6t, penim

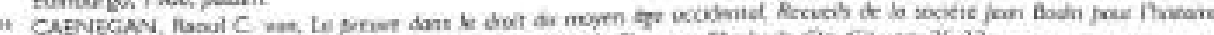

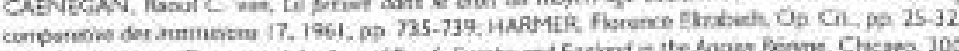

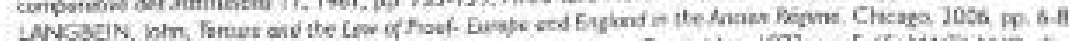

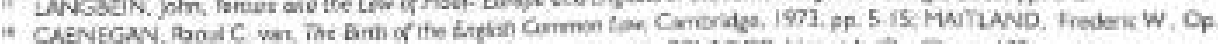

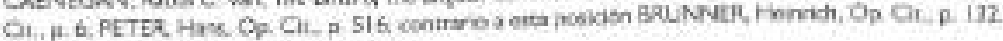

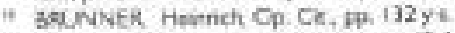

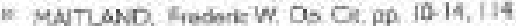

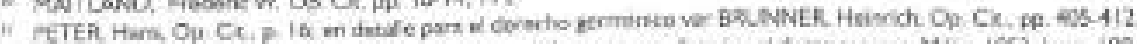

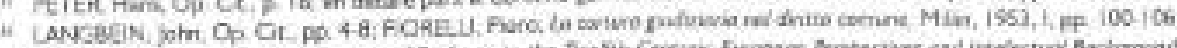

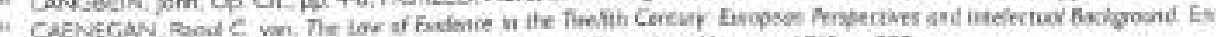

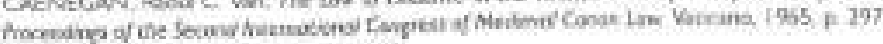

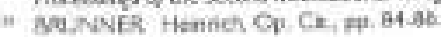


e irrpulso del preceso, semto para ordenar medidas que tengan por objeto el esclarecimiento de determinadss cuestiones. "Y Ya a medisdos del siglo XII al tey podia reclamar para si un doceminado process para avocarse directarmente a su conecimiento. Para ello simultảneamente se desigrabs un delegado para informar a los vecinss sobre la relaciba juridica respecto de la cual se requeria su opinión. Js Esta delegación para inquiri muy usual y claramente regulada en los nommendos teria su simil franco, solo que en estos era mis acotada y solo persanda en el solo ejercicio de autoridad (privileg) antes que en ejercicio de autoridad para obtener información rolavarte. "En los roxmandos esta orden emanada del rey recláó el noentra de "inquisitio", mientras que en el derecho franco se denominaba "indicults",

Durante la segunda mitad del siglo XII fue establecida la imposición de un acto formal del rey como presupuesto para la apertura del proceso. Este acto formal ordenatorio asumió distintas modalidaden según el tipo da procedimiente. El actor debia obligatoriamente acudir a las secretarias de consejeros letrados del rey (Chonicery) para solicitar all so emita la crden escrita del rey que luego debia ser entregada al funcionario competonte parz actuar jurisdiccionalmente. Esta orden recibió el nombre latino de "breve" o en lengua sajona "writ". Ela no solo contenia la orden oficial de apertura del proceso sino cue además referia a diferentes medidas coercitivas e impulsivas del jucio ${ }^{2}$ St la orden tenia por objeta principal, o úrico, el ínicio formal de un proceso recibia el nombre de "oniginal writ" o "breve originale". Dentro de la gran variedad de writs, es esta la que nos interesa en forma relevante a los efectos de podor hacer un paralelo con la institueión de las formulae y en defintiva de la "actio" del procedimento tamano clisico, "El "arigind" writ" conteria además de la arden del rey acompañada de formalidades especificas, una brove descripción de los hechos que, seguin el demandante fundaban su petición." Esta relación de los hechos sin entargo no erc efectuath por el propio domandante sino mediante un resumen efectuado por un escriba de la Choncery. Debide a ha reiteración de demandas similares en sus elementos do hecho y peticiones, las dodenes se fueron estandarizando en su formulación y contenido, arnbándose finalmence a la elahoración do formularios que permitian mayor agilidad y rapidez en su elaboración. Juscamonte estas fórmulas son las que curiosamente tienen gran identidad con las formuloe propas del procedimiento clásico romano. ${ }^{14}$ Si esta similitud es puramente casual o por el contrario existe una la influcncia remota del proceso romano clásico, o del procoso romano-itálice es un
incernogante que permanece asin abierto. ${ }^{2}$

\section{Los anglosaioncs}

Durante los sigos $\mathrm{V}$ y $\mathrm{V}$ la isla británica rocibe la inmigración da pueblos de ascenciencia germana-teutona ${ }^{14}$ Pucbios con instituciores juridicas que se imponen y desplazan al derecho romano vigente. "Uns segunda sorriente ingresa entre los sigjos IX y Xl conformada por daneses, otro puable de origen germano con derecho oral y fundado en la costumbre similar al anterior pero

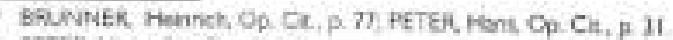

* PETEH. Hark. Op CE. p. 65

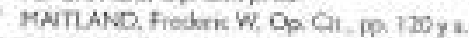

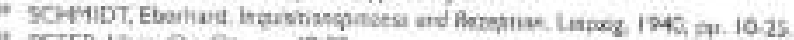

in PETER, Harn, Op Ot, pp 19.23

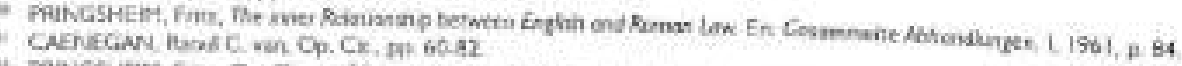

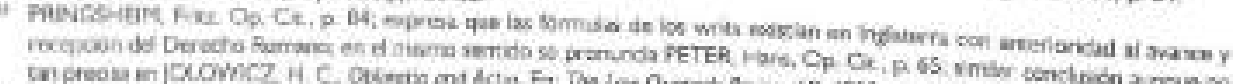

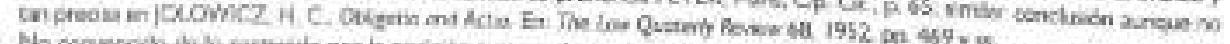

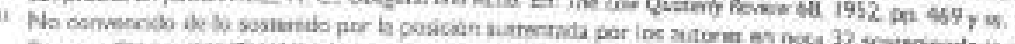

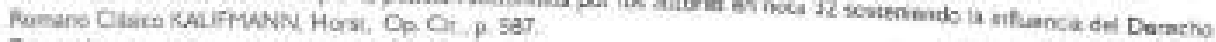

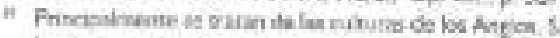

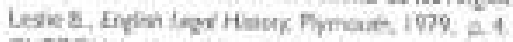

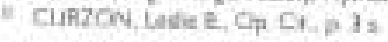


menos arganizado instipucionalmente. "Estas dos comientes antoriores impusieron un derecho consuetudirario que desplazó en muchas areas al derecho romano." La tercera corriente migratoria rambićn do un pueblo germane es la de las anglosajones con unt derecho corsuetulinario similar a las dos anteriores pero sin la fuerza y organización de quienes terminaran conquistando la isla en 1066, es decir los nermandos." Este constituye el purto de inicio histónico para la conatitución de un sistema furidico único, el cual bien puede ser descripto como un "sistema de acciones". En efecto partia de la scción o petición que se hacia valer bajo decerminadas formalidades para arribar al derecho tunelable." Se manilestó no mediante la actio sino por un writ. Esta axpresión en su significado inciuye a la acción, a la flermula, a la demanda, en dafirvitiva cualquier acto revestido de ciertas formaldades que tenga aptitud para iniciar o impulsar algún proceso judical." "

Es poco conocido el derecho y en especial el proceso judicial de este periodo. Su principal ciracteristica estí marcada por la in suencia juridicas germana-teutora como sistema mucho miss fuerte e imponente que el syjón. Tanto insular como contimental el derecho germano nuvo una gran influencia marcadla por la unidad entre al derecho procesal civil y penal fundado en muchos ritos destinados a daterminar sobre ol demandado su culpa o nocencia. "Girabainicalmente en tomo a la vengenzaprivada institucionalizada. El proceso era de las partes y solo interesaba a clas. Ls participoción del juet tenia solo por objeto dar garantia de institucionalided pero su rol era sunamente pasino. "La participación de los vecinos era relevante y el recirso a medios de pruebas para mirimizar o directamente excluir las dudas en el juzador, llevó a regular instrcuciones como les ardalias y el dualo que tandian en definciva a brindar la mbxima certeza y a exciür posibles arbitrariedades del jizgador" El emplazamiento del demandado se efectuaba como un acto privado sujeco a la puesta del sol come punto lerite que determinaba el conocimianto que debia tener el demandado ensu lugar de residencia y, en su auserxia, su seniors o servidumbre. Lo que podia ser acredinado modiante testigos. "

El conteride del emplazamiento debia ser de forma tal que se cemunique lo requarido por el actor al demanctado intimánd olo a compareser ante ef trisunal. Habienda comparecido el denandado. ol actor debia bajo jurarnento ${ }^{-1}$ repedir su demanda por ante el tribural, Recién entonces podia dirigirse al demandado de acuendo a rigidas fómulas preseritas. "

\section{Les Normandes y el surgimiento de los writs"}

Con la conquista normanda ve produjeron dos cambios juricicos-processies importantes, aun cuando el sistema sajón no fue radicalimente modificado. Por un lado se estableció una jurisdicción eclesiásticat, y por el ocro se simentó un sistema feudal con sus propias reglas de aplicación de la coerción y resolusión de conflictos." El gran cambio tiene lugar bajo el renado de Errique Il (1133-

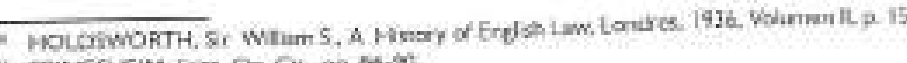

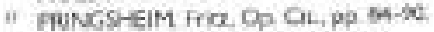

4 FeTEl, bivas Cp. Cit. pp 19 y 65.

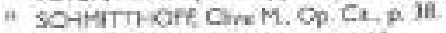

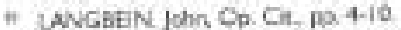

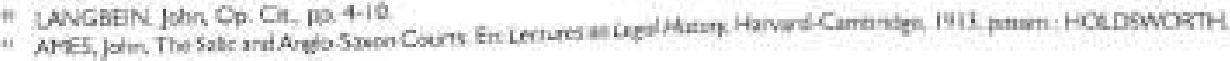
Io Wham 5., Op Ct, p. 103

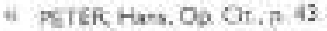

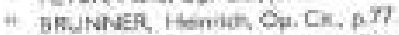

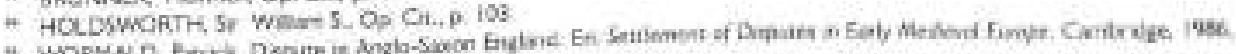

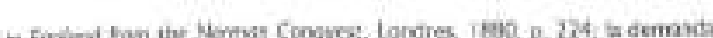

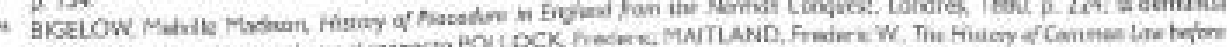

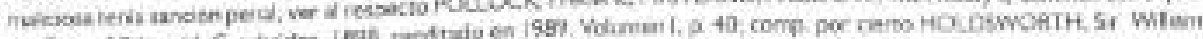

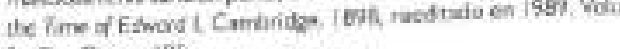
S. Op Ctip atos

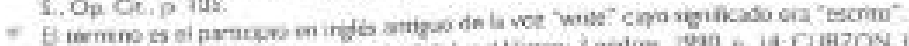

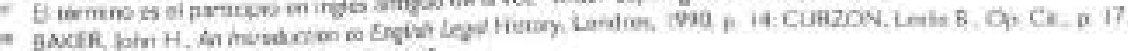

- CuRzoN Luit in Oa Cit, pa 17, 148 
1389) mediente le cresción de las Cortes Resies. Sus funcionarios actuaban en calidad ce empleados del rey y para la resolución de les díterentea casos debiar acudir obligatoriamente a la cosambre local y a las raglas que iban coniormando el derecho común (Commen Law)" Paralelamente se desarrolló la juriadicción eclesistica (Curia Regis) con tres tribunales que entendian en cuestiones diferentes. La Court ef Exchequer entendia en cuestiones tributaria La Court of Cammen Fleos cra competente para todas cuestiones civiles. La Court of King's Bench representaba ks jurisprudencia de incerds reievante para ed roy y se superponia en muchas cuestiones con la campetencie de la Court of Common Pleos. Sal función principal radicaba en la superylsión de la jurisprudencia de los trburales inferiores."

\subsection{Writs hastas el siglo XIII}

A partir de Enrique ll, al rey podia auscarse directarnente para cenocar un prociso que haya sido tramitado por ante las corte reales medianse uns orden dirigda al Sheriff u atra furscionario judicial. Esta orden se denominaba Writ o Brevio." Estas órtenes escritas pedrian conterer la indicación de alguna medida judieial a tomarse. De esta forma por un lado, se presentan como irstrumentos para la aplicación de la voluentad directa dal rey. Por atro, parse el proceso judicial stgnificaba la posibilidad otorgada al demandante para abtener-pravio plgo de tases- de parte de los consejeros juridico reales \{Chancerv\}, estas ördenes dirigjas a los funcionarios judiciales que estaban entendiendo en dichas causas."

Los writs con ol timbre real contenía los nombres y la diresción de las partes, una breve descripción de los hechos desde la óptica del demandarte y la orcen del rey que, de acuerdo a la relación de ks hechos, se dirigia al derrandado exigiendolo determinada conductn. "

Rex vicecamiti salutem. Quescus est mihi $N$, quod $R$. iniuste et sine iudicio desseisinit eium de cammun pastura sua in illa villa que perti net ad libenum tenementum suum in eadem villa vel in illb alio willa, past uitimam transfretatianem meam in Normanniam. Et ideo tibi precipis quad si predictus N. focerit te secinum de clomare sus prosequende, tunc facias duodocam iberas et legales homines de vsneto videre pasturam illam et tenementum, et namina eorian inbrerion. Et sumane eos per bonos sumnorvitares quod tunc sit caram me vel iusticis meis paras kide focere recogrvitionem. Et pane per vadum et solvos plegios predictum $R$. vel boolinum suum si ipse inventus non fuerit, quod tune sit ibi ouditurus Wlam recognationen. Et habeos ibi summonitoves et hoc breve et nomina plegionum, Teste etc: 13

La similitud del contenido y la ralación do los bechos cost otres writs dietados con anterioridad, llevo a que paulatinamente los funcionarios de la Chancery acudieran a formulas de redacción similares o identicas. Elio conduje a la elaboración del fórmulas predispuestas para la tutela de determinados derechos en base a la casuistica del derecho tomín (Common

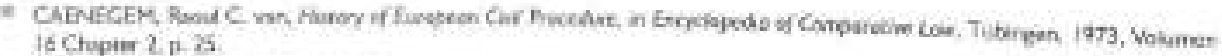

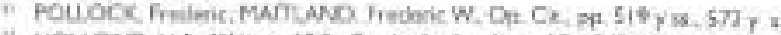

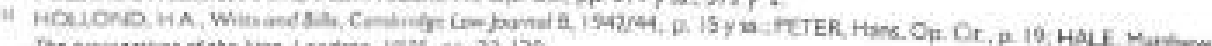
The peicgetios of the are Londres, ivrs, pa. 23-120.

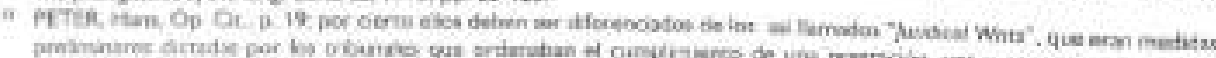

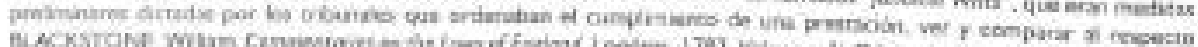
Fioderic MNTILND Fiedaris W. Op CF 10 10

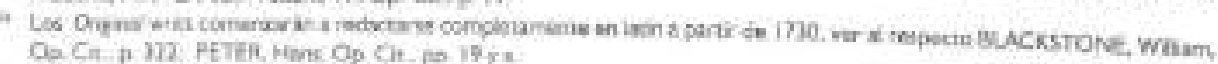

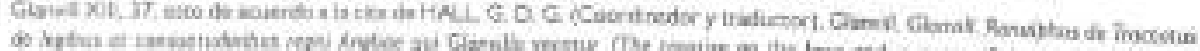

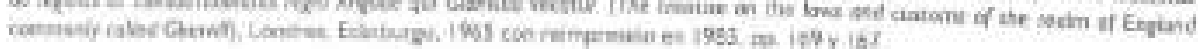


Law) ${ }^{\text {st }}$ Ya en al sigjo Xll era conocida una recopilación de las principalos fórmulas. Asil la tarea de los funcionarios reales solo se limitaba a cempletarlas con el nambre y domicilio de las partes simplemente.?

A lo largo del tiempo estos empezan a recibir designaciones especiales acorde al derecho que se haria valer. Al Asi surgen las designaciones de Writ of novei disseis in. Whit af night, Whit of detinus, Whit af mert dianceston. Whit uf debt, Whit of tresposa, etc que denotaban el derecho material cuya tutela se requeria." Las fórmulas contenian un saludo al funcionario a quien se dirgian concluyendo cen la orden del Rey de acuerdo a la petición solicitada "C A b largo del tiempo se multiplicaron los tipos de writs, lo que apsrejo la modifcarión del mecanismo de injeio del proceso, a lo cual se debiá adecuar la administrzeión de justicis. Con elo tambièn se debieron incorporze nuevos supuestos de hocho, la que no solamente impleaba la crnación de un nuevo writ, sino que ello debia ser debicamente justificado, Ello Ievó a dar compecencia al rey en cases del Common Law para controlar los nuevos writs."

Asi la dependencia del derecho que se invocaba con el writ mediante el cual se lo hacia valer se manifestó con la expresión "no writ, no night", en tanto el accesa a la justicia dependia de la preoxistenciz de un writ decerminado que contemple el derecho que se queria haces valer. No tardó mucho tiempo para que se crearan nuavas förmulas o bien, se modaficaran las ya existentes surgiendo simultáneamente la rocesichad de eíaborar cuerpos orderados, tarea que fue iniciach por los funcionarios de la Chancery. "Eitas colecciones provienen de 1227 y fueron considerads oficiales designainsade come Register of (originol) Writs."

\subsection{Origen de los writs}

Las órdenes reales escritas en lengua sajont existian ya en el periodo anglesajón y contirüan con el dominio narmando, pero sin fórmidas fijas. Estas recién asumirán este rol cuando se le asignen la función de medio para iniciar el proceso en ol reinado de Entique IL th Es entonces cuardo so introducen los formularios tomados del procedimiento de cognición nomanda. los que a su wez tienen origen franco. Los antecederses se ramontan muy mediacamonte al periodo romano tar dio. Estos fueron sistemáticamente compilades por Cassiodor (490-583) como ministro y juristz ostregodo :" En todos mstes formularios la estructura y contenido ardenscorio as simvilar y su recepción tiene lugar en ba isla con los. Whits proecipe quod reddat"

\footnotetext{
- CAENEGEN, Futwic van Op Ct, p 60

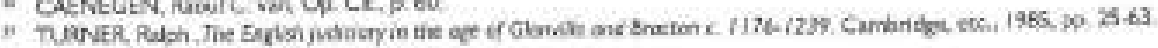

in peTrk Hana Os. $\mathrm{CH}_{2}$ a 30

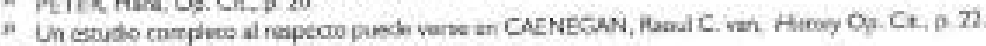

- PETER Has Os Cr. par 21 y is

- PETER, Han Op Cr, p. 4 .

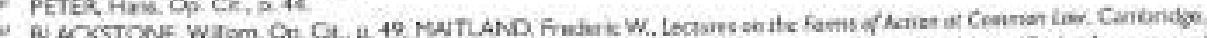

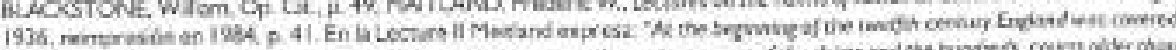

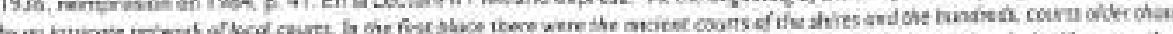

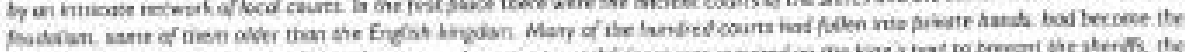

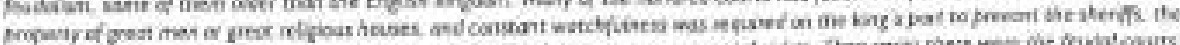

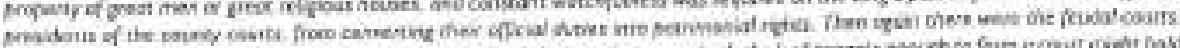

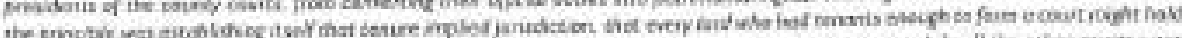

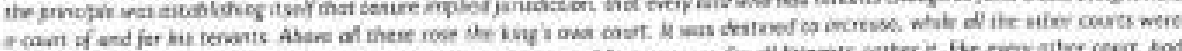

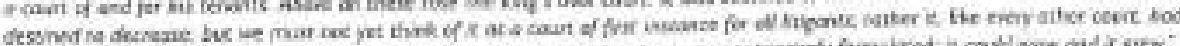

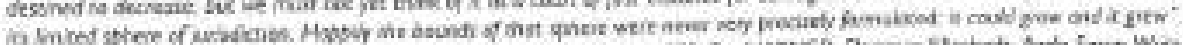

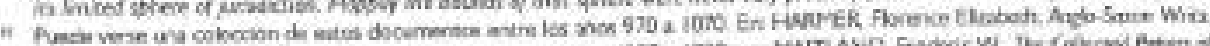

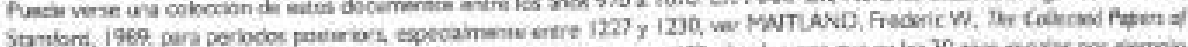

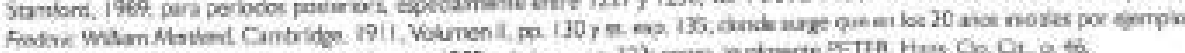

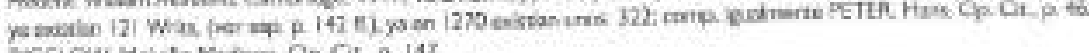

AxGELOW. Metvlo Mogitum Os Cit.p. IAT

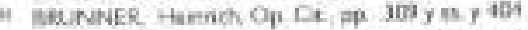

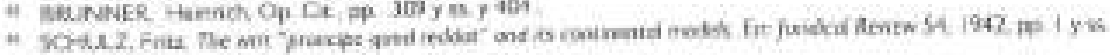




\subsection{Dictación y notificación de los writs}

Los writs oran elaborados en la Chencey a potición del demandonte sin avodiencia doi demandado. De acuerda a lo peticionado correspontía un determinado writ, quedando en iranos del dermandarte el elezir aquel que sea el adesuado para su pretensión. Si bien iniciaimente el número de writs esistentes noera numeroso y consecuentemente no conlevaba tanta dificultad su selecciön, no siendo mayor taron ta del secrecario para elegirlos, con el paser el tiempo aumertó considerablemente su número. En a sigjo Xill se escablece un arancel a pagarse por pligina "Una vez que era escogido el writ, completado los datos que se requeriva y pagado a concespondiente arancel aquel era timbrado y natificado al titular del tribunal, quien debia prosoder a notificse al demandado con constancia de rẹcepción (Recum of the Whit, Solo excepcionalmente se podia notificar directamente a este ültima, *

La importaneia del writ no solo radicaba en ser el escrito que daba inicio formal al preceso sino que ademas determinaba la estructuración de las sucesivas exapas procedimentales: th competoncia del triburnd, las formas en las citaciones e intimaciones, los requerimientos especificos sobre al objete que se solicitaban a las partes (Fieduings), plazos, los distintos medios de de pruabs admsibles Quramanto, jurado, duelo), raglas aplicables en casco de rebeldia y hasta las distintas alternatives para llegar a la sentencia definétiva y la sibsiguiente ejocución da fa misma ${ }^{*}$

El writ remstia también un importante sigrificado en relación al derocho material. En especial el Original Writ determmaba las normas maser isles en tase a las cuales al juez debia pronunciarse sobre los hechos alegado por la partes. Asi estas solamente terian que alegar lo relative los bechos sobre los cuales funtaron su posiciōn, Era actividad exclusiva del juez proxurar y determinar al derecho aplicable (iuva nowit curia) " Las distintas reglas juridicas a sar aplicadas fueron desarroliándose a lo largo del tiempo en la príctica judicial, acudiendo los jueces frecuentemente a su empleo por analogia anas similisud de los hechos y conflictas planteasos. Asi la decisión de cual nomma juridia ora aplicable para un caso determinado debia efoctuarse de acuerdo al cantenico del Ongind Whit, el que recortemos era escogido por el actor, Así si por ejemplo si se destoba demandar una determinada suma de dinero, debis acogerse el Whit of debe. "ni se debia tener en considaración una contraprestación cumplida por el demandante debis acudirse a otro tipo "considerution, quid pro ços". Si lo requerido se encontraba documentado en un titulo privado debía acudirse Writ of convenont. Si se requería el resaramieneo de daños y perjuicios debla acudir a otro Writ. $Y$ si no era posible incluir la pretensión on unos u cares tenia la posibilidad subsidiaria ded Writ of tresposs on the case, " Los distintos supuestos do hecho no surgian do lo contenido o expresado en los distintos writs, sino más bien de las distintas nomas juridicas desarrollada por los tribunales en base a aqueles. La actuación jurisprudensial era por demás pruderte. De esta manera no siendo ta exposiob́n de los hechos ajegado por la pacte la adeciada y correcta para el excao de determinado tipo de writ, la dervanda era rechazada por inadmisible. Para ello era suficiente que el tribural arribe a un comvencimiento de que las hechos alegados diferian de les hechos adecuados al writ que se hizo valer. Esto era rigurosamente seguido en la práctica rechaándose frecuentemente demandas por no ser bs alegaciones de hechos adecuadas al wot que sa hacia valer." Eata sentancia desestimatoria de la demanda ne impedía que

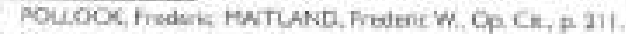

- PERER Farm, Os Co. a 20

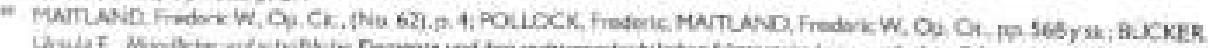

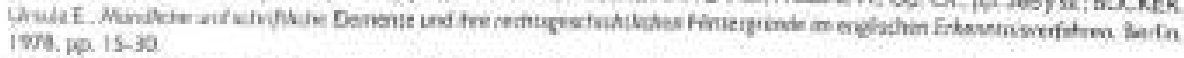

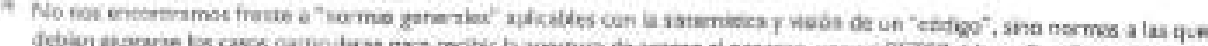

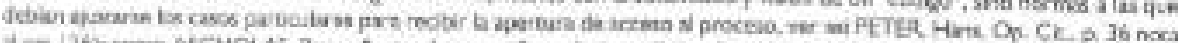

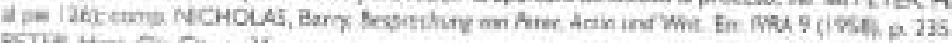

PETER Han ON OL. p 26

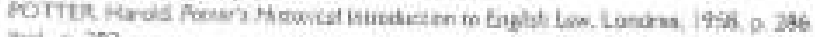

bed. 2.28 ?
} 
el actor podiera escogor un nuevo writ para interponer una nueva demanda, por ciento elevándose el costo del arancel a pagar $y$ de algura manera dilatando la iniciación dal proceso. ${ }^{*}$

\subsection{La multiplicación de les writs y las lagunas legales}

Hasta ef siglo XIV la Choncery logro solucionar parcialmente la enerme multiplicación de nuevos o recidados writs. Es entonces cuando puede considerarse conloemado un verdadero WirtSystem. Ello es la tocalidad del derecho privado ya no fue organizada de acuerdo a los fundarnentos del deracho material o aquello que las partes solicitaban, sino que se estructuró y siatematizado en base al recurso o tutela procesal que al respecto se ordenabs. Sobre cllo se diesarrollo el Cammon Low creándose y haciendo uso de nuevos writs. Esto es precisamente lo que tiene muchos puntos de conexión con la visión del derecho por acciones del derecha fomano honorario siendo que para ura obtigacio corraspondia una octio" "La desestimación de una demanda por el defecto del writ escogido erreaba cierta seguridad y consolidación en las decisiones juabiciales", pero a su vez elavsba Is tarka de la Chancery y ol peso del tiempo an el requirente de tutela jurisdkcional."?

\subsection{Limitaciones al poder de la Chancery para la dictacion de nuevos writs en el siglo XIII}

Durante el siglo XIII para fortalecer la posición de los nobles, se ebtionen nuevos tipos de writs que fueron paulasinamente consolidando el poder jurisdiccional de tar cortes realas. En la Charta Mogna de 1215 fue explícitamente rezulado que los Writ proecipe quad redalat podian sor otorgados solamento a los vasallos de la corona." Ello, en otres términos, cuando el actor sostenta haber recibido su feudo en forme directa del rey, teniz derecho a solicitarbs. Esta limitación se tradujo posteriormente en una demanda con su correspondierte Writ (of novel dissenvin luegr deverido en Writs of entry) de carseter netamente posesorio"? El resultade de la evolución antes. descrita, se tradujo en ina corpetencia seribuida a las cortes reajes, no importando finalmente st el bien cuya posestón se discutia habia resultado o no de un feudo otorgado por el rey. Le bastaba al demandante alegar que ol demantiado decentaba el inmueble ilegitimamente." A mediados del siglo XIII se limitaron aju más las facultades de la Choncery, en especiel nodiante las disposicionas conocidas como Prowsians of Oxjord ded asio 1258. Alli se estableció que un nuevo Writs solamente poda crearse por el acuerdo del magnim cancilium, que ustaba intogrado por vasal los del rexe" Bajo ef reirsado de Eduardo 1 (1272.1307) comienza paulatieamente la participación del partamento para la creación de natvas layes (Stotutes) ${ }^{\text {at }}$ Asi el Statute de Westminster if de 1285 tumo por objeto especifico la regulación dela dictación de nueves Writz. "Se dispuso que nuewos Originot Whats podian ser despachados siempre y cuando existiera consenso del parlamento ${ }^{24}$

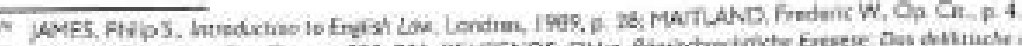

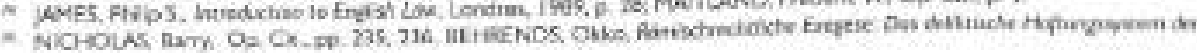

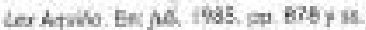

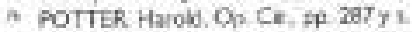

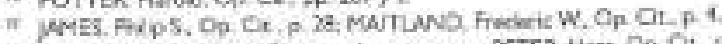

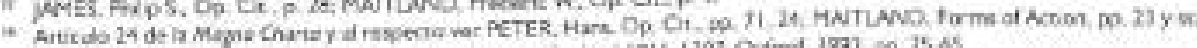

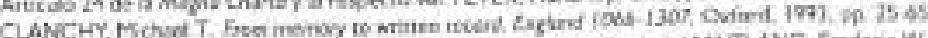

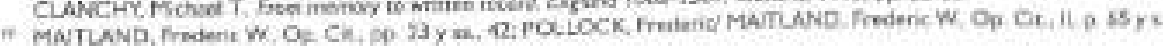

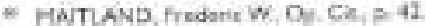

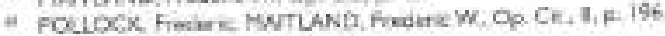

* FETER Hane Op Ce in 7 Y ss

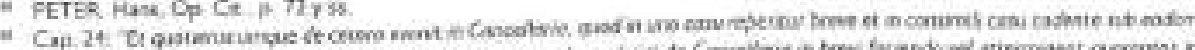

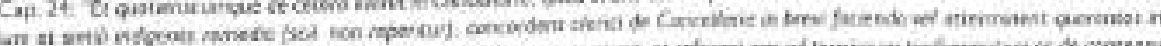

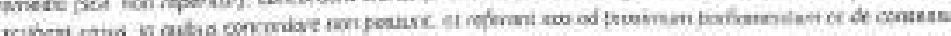

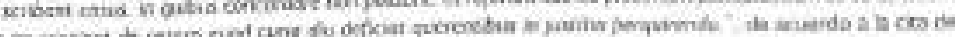

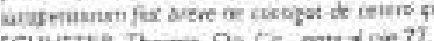

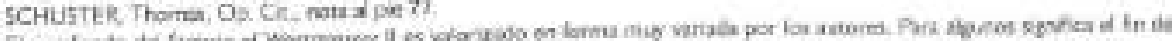

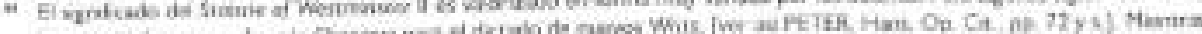

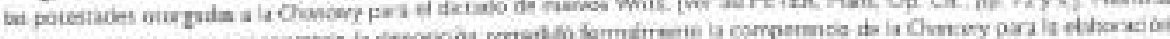

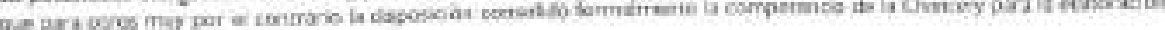


De esta farma a la Chancery le quedaba solo la posibilidad de poder emitir writs siempre y cuando denoten pequerias variaciones de los ya conocidos (Formulare in consimili casu). "De esta mancra se arriba a una solidificación del Writ-Systems en materia de derecho inmobiliario y feudal. La facultad de eminir Writs in consimií casu fue empleada por la Choncery especialmente en materias vioculadas al derecho de los contrates y de responsabilidad por delites. ${ }^{\circ}$ De esta forma fue ampliado el Whit of trespuss upon the speciol cose, al que hasta 1360 estaba sólo limitado a determinados supuestos de ilicitos, siempre que haya existido uso de violencia. Asi en el Writ of tresposs in assouft and bottery se tendita a la reparación de los darios a las personas mientras que en el Writ of tresporss de banis osportatis se reguardaba el daño a las cosas." Con posterioridad comienza a ser aplicado en los casos de vicios a la woluntad contractual no solo modiante violancis sino también en caso de sngano" En forma paralela al desarrollo antes descrito se va consolidando una adecuada redacciōn y registro de los diferentes Writs mod iante el Register of Writs,

\section{LA EQUIDAD: EL SURGIMIENTO DEL SISTEMA DE EQUITY ANTE LAS INSUFICIENCIAS DE WRITS}

Como un sistema paralelo al Common Law so dessrrolla a partir del siglo XIII al sistema de Equity. Este no sólo implicó un derecho privado paralelo, sino adernás la creación paulatira de un sistema procesal propia. Las causules de su suaglmento pueden ser atribuidas -entre otras- a dos elementos propios del procedimento del Commen Law. En primer lugar el riespo que corria el demanciante al no hacer una comecta elección del writ adecuado para el procedimiento. En los hechos inplicaba la imposiblidad o al menos la dilación en el resguardo do su derecho reclamado. No siendo perfectamonte adocuado a un determimado writ el derocho que se pretendla hacer valer no resultabe tutelado." Ademis siendo la cuantia de la domanda muy elevada aun cuando resultaka evicierte que correspondia sea reconocido en favor del demandante una porción de lo requarido, la regulación estricta de las formas implicaba en las hechos el rechazo de la demanda. En segundo lugge el derecho material quedaba en un segundo plano en reisción al procedimiento, revistiendo tal dopendencia que apenas resultaba relevante. "A ello se sumaba ls inexistoncia de una segurda instancla. Solarnente exista la posibilidad do impugnar ef protocolo judiclal mediante Writ of error pudibndose revocar las sentencia solo en los supuestos erreres, reenviando la misma para una nuervas decisión. A partir del siglo XIII el demandante podia acudir directamente al roy quien se debia pronunciar conformo justioa. De esta manera fue frecuente acudir al roy a los efectos de que revise las decisiones adoptadas por los triburales del Cornmon Low respecto de las clajes el agranado invocaha una injusta aplicación del derocho (avisdiction in error). ${ }^{\text {N Ello }} 59$ hizo aùn más usual en el siglo XV lo que condujo en los hechos a la configuración de variados procodimentos debido a la sobrecarga que teria el rey delegardo estes funciones an sis consejeros. En caso que la pecicion se dirija a solicitar la motificación del derecho materal o procesal, ello era docidido

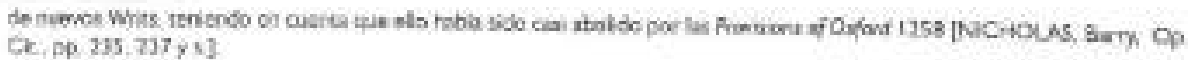

n Martuaro, Fraterk W, Op Di a es

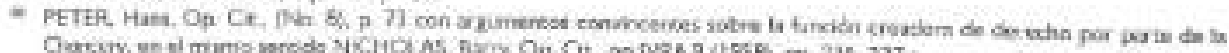

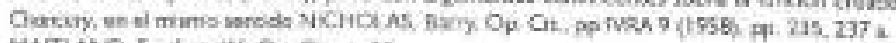

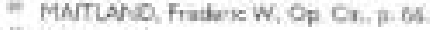

* itid, $\mathrm{f}$. 0 .

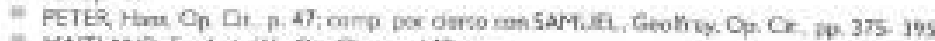

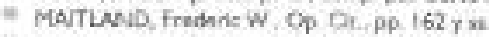

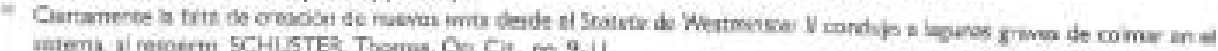
watema ai reiperm SCHISTER. Thorm, Og. Clt, pe: 9-il

* WMES Autps, ap Ch, p 20

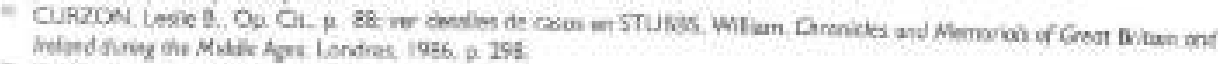

BAKE, Jinit, Q. CX, o il 13 
por el parlamento, asumiendo la resolucḱ́n carácree de ley dercgaroria. Ahors si se trataba de un conticso privado sin mayor relevarcia su resolucibn ena delegada a los miembros del corrseje real, por ejemplo al Chancellar,"

El procedimiento de equidad se diferenciaba sustancialmente del de Comman Law. El Choncellor era quien cumplia la función de juez y decidia sobre las cuestiones de hecho y de derecho sin incervencićn del jurado. " De esta manera, on la prictica al eargo lo desempenaba un jurista responsahle encargado de resolver las cuestiones sujeras a su conocimiento. El Chonceifor gozaba asi de mayares facultades como debores para lograr el correcto exdarecimiento de los hechos, yo que debia investigar en forma plena y completa la controversia a decidir. Esto tambión inclúa of solicitar las declaraciones de las partes y de testipos." Sin embargo también en este procedimiento regia el principio dispositimo, correspondiendo a las partes iniciar el proceso y fijar el abjeto de la litis." El procedimiento era informal y de sencilla tramitación, justamente contrario a las causales que obstazulizaban al buen funcionamiemo del procedimiento on el sistema del Common Law."

El inizio dol procediniento de Equity se diferencio del Comman Law en primer lugar porque el primero precisabe solo de un writ , Iamado Wht of subpeena, medance el cual se emplazaba al demandado brijo amenaza de pera de oficio por ta Chancery. ${ }^{10}$ El Wit $\alpha$ subpoena no tenia nirgún significado material, simiendo solamante para la citación del demendado. Es decir se trataba exclusivemenke de un furidkal Wit con una naturaleza diferente a la del Onginal Writs ${ }^{10}$ Si bien inicalmente era sificiante fa simple petición por arte la Chancery para el otorgarniento del Wit of atpeenat", posteriormente se

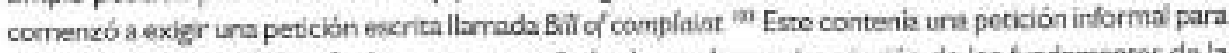
ef ctorgamiento dal Wrít of subpoena acompaniado de una breve descripcián de los fundamentos da la petición, no siando ello tar esericso como la formulación exigida parz el Originot Wric. Con posterióndad se desarrollo un escrito modelo que conteniz el nocrbie dal demandarte y demandado, el objeto do la demanda, ta conducta reprochable del demandado y los daños ceasionados, el as avio a la equidad y la petción de lever abelante el procaso. in El Bill of complaint represena la primera oportunidad mediante la cual el demandanse podia manifestar su petición con una relación sucinta de los hechos sobre los que la fundaba acomparaudo be una breve descripoión de la pruaba. En definitiva les hechos sobre los cuales se debà decidr y la prueba que debia rond rse surgian del Bull of comiphaint y de la conducta que asumiera el demandado oporiéndose o no a la patición del actor:

\section{LOS TRIBUNALES MARITIMOS Y LA RECEPCIÓN DEL DERECHO ROMANO}

Paralelos a los tribunales del Coniman Law y la jurisprudencia de Equity se desarroltaron otroc que tambièn eran competente para enkender en cuestiones ctulies. A partir de 1070 se desar rollan en Inglaterra los tribunales eclesiaticos ${ }^{106}$, lo que fueron compacentes paralelamente los tribunales secularas en cuestiones vinculadas con derecho de farmilia y sucesiones. Hasta la reforma fueren parte do la organización judicial inglosa viniendo al Papa como instancia Litima y superior: "Ar Ante

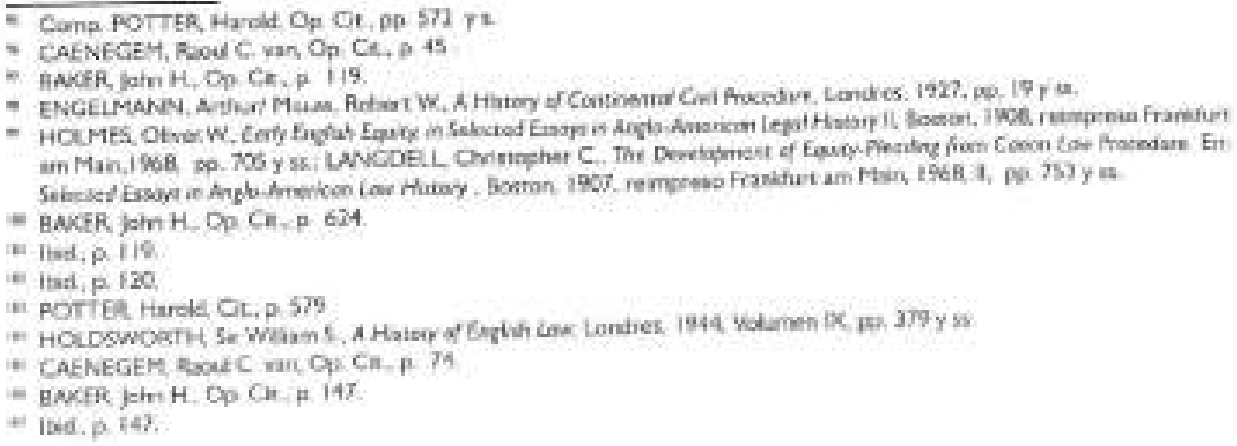


los tnbunales celesiasticos ge observabe el procedimiento romano-canónico el que permaneció inalterabie y no influencado por el precedimiento secular. ${ }^{\text {ita }}$

Especial imporzancia revirtieron los triburales en derecho maritimo (Court uf Achirolty), surgido como tribunales especiales diroctamente consthuido por la Curia Regis. Debido precisamente a la dificulad por la especta materia que significaba sl deracho marítimo y lo complejo del procedimiento surge la necesidad de la constitución de estos trbunales. Aquil resula muy imeresante el hecho de que la Court of Admirolry aplicaron el proceso romano-canónico que era emploado par les tribunales eclesiśsticos. El principal obsticulo era la aplicación do ia institución del jurado propias del Common Law para que se optara por el proceso romano-candnico. Ahora bien no es precisamenta extrano, ya que el derecho material maritimo que era aplicado estaba fundado principaimente en principios del dereche rocrano.

\section{ACTIO Y WRIT}

El interroginte sobre los origones ramanos ciel sistemainglès de derecho privado conformado a partir del procedimierito no admite la respucsta inmediata de un fundarnento acudiendo como directriz única al derecho fomano clisico, A partir de la descripción que se hizo de la paulatina formsción del sistema de writs, podria quizís servir de fundamento justamente para sostener una ciarta influancia romana a través de los normandos, Ambas afirmaciones son parcialmente correctas. Sin embargo, es posible formular una tercera hipótesis que predique la influencia conjunta tarito romana cano del derecho normando y franco. "It El estudio de algunas de las obras de los prinepales juristas de la época servira para demostrar el trasiondo en la ewolucéb histórica del sisterna de los wrís.

En la obra Troctutus de Ranul Glanviell cancluido entre los años 1187 a 1189 se llegan a mencionar sotenta y cinco diferentes formularios de writs de los cuales diez son Original Writs. "W De este total algunos fueron incorporados directamente desde la Normandia La elaboración bibliografica de los glosadores comienza z desarrollarse recién luego del ato 1170 an lo relacionado con los requisitos y principios procesales en torno a los libelos que sirviaren de base para la claboración dol pensamiento del sistema por acciones en Italá. El resultado en la pràctica fue la creación de los de loa ibeles. Es posible ver mucho ances de la ìffuencia romano-itilica la imposición de fórmulas para petcionar la tutela de determinados derechos y para la realización de algunos actos de impulso y traminación del procedimierto." En el tratamianto de los diferentes writs Glamiell da fundamento a un concepto y término procesal qua se convertirá en el centro de su sistema: la petitio. 19 Si bien este têrmino no recibid la misma atención y ralevencia en la praxis y dogmitica rornana ni romenoit:lica, ellos se debib a que la voz actio era empleado casi como sironimo al menos en sus alcances. Asi es pesibie constatar ef uso de peititio en Placentin y en Glanviell. Aun cuando aste último y el resto do los jurśstas de su tiempo hayan podido tomar de los glosadores ciertos aspectos, por el selo dato cronológico de la preexistencia del sistema inglés de los wrís no parece acepcable sostener cronoibgicamente la influencia directa de las obras romano-itilicas de les glosadores, "I" Si es posible iostener que Glanviell empleó las claboraciones del derecho romano itálico para dar una concepción sistemática y ordenada al sisterra ingles de los writs. Mis aúm, puede afirmarse que precisamente

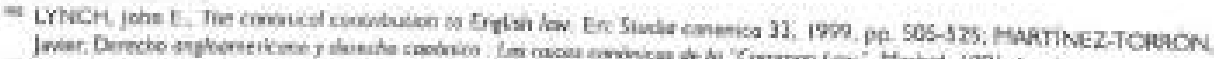

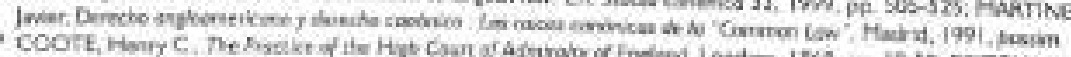

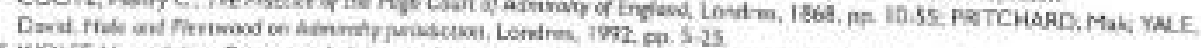

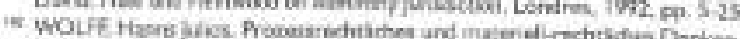

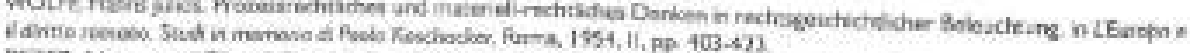

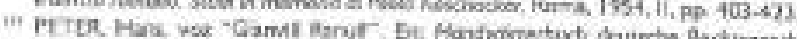

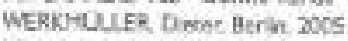

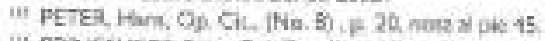

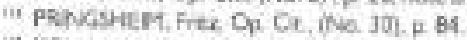

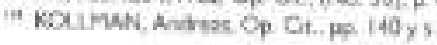


porque para Ganviel ya era conocida la estructura por fómulas y al funcionsarniento del sisterna ingles, elo factitó y ao determinó la incorporación de las noclones éaboradas por los /uniscas romanoitalicos. Y que, por su similtud y er su caso idertidad con un sartema precxistente la elaboraciones efectuadas no eran extrañas ni desconocidas para los jurlaras ingleses de ese tiempo.

\section{Infuencia del Deresho Romano-ftalice nérdice}

Mientras en el norte de italla la actividad de los glosadores se concantraba al estudio del derecho romano en base al Carpus luvis, en inglaterra la rexepción do las alaboraciones eran tamizadas por el dereche zermano (que sí ruvo mucha influence en el norte de ltaia) que impregraba de una manera enpecial la praxis judicial y la vision dal derecho. Dentro da las prácticas germaras ha paticiones de las partes eran consideradas camo alegaciones de dececho, lo que era sometido a un riguroso sistema de prushas legales, rituales y on muchos casos irracionales en su valoración. 16

En el norte de ltalis se desarrolía en la práctica zun antes de les glosadores, un procedimiento dentro de los tribunales secularas asentado sabre las tases germánicas de los longabardos y fuerternante influenciado por el Corpos luris. "T La irfluencia germana en el proceso se manifiesta en ha exigencia de que el actor manifieste su pretensín mediante fórmulas que exterioricen alęaciones de derecho." Asi por ejemplo, Placensin sostenis la necesidad de la mención de la octio, o sea el derecho, como requisito do la petición qua se desenba hascer valer." En su "Summa De. Autionimn varietatibus" (II 60 ) el desarrallo que efectía de la Actio no se corresponde ai significado y sentido clasico adjudisado, sino exclusivamente como continente de una manifestación o alegacián de derecho equivalonta a lo que la parte pretendia tacer valer ("ratio") dentro de un proceso. Asumia asi una naturaleza netamente procesal, ${ }^{13}$ La petición efectuada por la parte era de carácter procosal (hotonatio/petitio) la que contenia una alegación de derecha que le daba su racón de ser (ectiajatio). Sestuvo as i la idea de que no era necosario formular una demanda como octio en términos estrictos. y riguresos. Asi el actor podia formular su demanda en términos generales. ${ }^{21}$

Paralelo a este desarrollo en la practica forense del norte de italia se incorporó la exigencia a partir del aro 1130 , de que dicha alezación sea electuads en forma escrita mediante un libelo. Ello representa una clara influencia del derecho ramano y algo extranio al gormano. ${ }^{13}$ Fue recienz $z$ partir de la segunda mirad del siglo XII qua se vincula la alegación de derecho de erigen germano can lo mencionado en el Codex Tit.2.1.3 como Edictio actionis, Ello tuvo por consecuencia esencial el resurgimiento de las estructuras tásicas del clasico proceso formulano del derecho romana. 'tid $L$. obra de Bracton "Tractotus de legibus et consuetudimbus regni Anplioe", escrita entre 1250 y 1256 , por cierte son el mismo titulo de is de Ranulph de Glarvili, escrita 60 arios antes (1 I B7, editada por primera vez en Londres, er I554), constituyen la primera base de sistamatización cientifica, con base romanistica del Common Law.'2t Las dos obras estin ligadas al fenómeno de ha "Rocopeión" del Derecho rorrano en hglaterra, que comienza a producirse a mediados del sigjo XII a través de

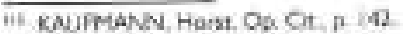

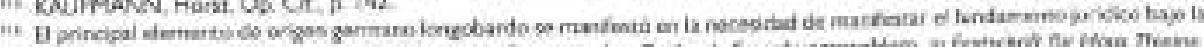

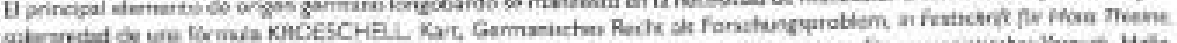

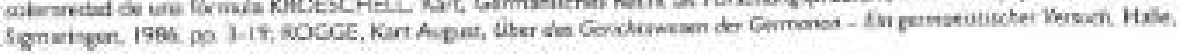
1020 .79. 4.14

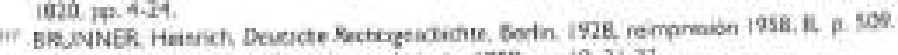

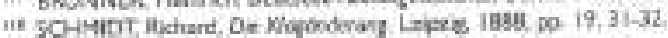

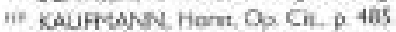

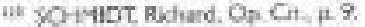

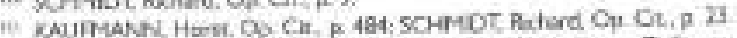

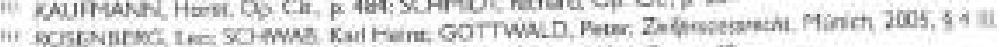

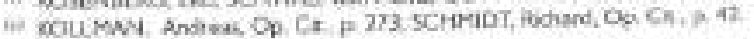

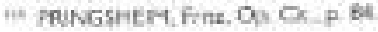


Vactria. Ambas producciones fueren formalmente ramaras pero con un cocitenido en lo sustancial netarente ingles o para inglaterza, ${ }^{13}$

\section{Influencia del Dereche Romsne-Cinonice}

Paralelo a cste desarrollo del derecho procesal secular germano en el rorte de italia, el derecho candrico comienza a exigir a lo largo del siglo XII, un libelo de demanda. Sin embargo, la prues del derocho oclesiástico se negó a exigir la mención de la octio dentro del escrito. Muy probablemente se debió al rechazo del derecho materal romano como base de juzgamierto que no cra sino un temor del derecho canónico por verse obstaculizado en su desarrallo o desplazedo por aquel. No tuvo en la conformación del sistema Inglés mayor influencia en un sistema ya preexistente. 13

\section{Comparación entre el sistema inglés (Writ-system) y el dereche remano clásico: vidas paralelas $y$ no derivadas.}

Habièndose desarnollado los principales puntos de la formación y desarrollo del sistema inglis y remitido a los puntos de contacto con el derecho romano clisico y en especial el derecho formulario, es que conviene ahora precisar las coincidencias y diforencias.

a) En el derecho romano clisico el protor mediante el otorgamiento de la tutela da darseches por acciones (actio) creaba derecho. Laoctio por si misma conteriaun prest puesto de hecho material que por si mismo no era derecho material, El orderamiento juridico estabs conformado por un ordenambento de acciones. De manera similar en el sistema inglés del sigjo XIl el Chancelor en la elaboración y creación de un writ para deterrirsdos casos debia hacer una descnpción de los hechos que servian de fundamento material para el éxito de la demanda. El writ porsi mismo no era sino uns manifastación procesal, corsocucntemente el surgimiento del sstema iridico del Common Low no era sino in ordenamiento de writs, "1' Tanto la octio camo el writ eran institutos de naturaleza y man festación netamente procesal cuya correcta clección implicada la consecuente accojida o no de la tutela del derecho que se invocaba ise

b) Así como las distintas actionen so integraban en un catilogo ordenado (album), ello se corresponden en el derecho ingles con el Register of Whits. Una vez escosida la comespondiente actio o impetraba el adecuado writ implicaba respectivamente que, ef pretor iniciaha formalmente ol procesimiento in iure otorgando esa virtialidad a la acción incoada foctionem) dare), a pari ef Chancellor dando el correspondiente writ ora una orden escrita destinada hacia el tribundi comperente. En ambos casos no puede sostenerse que haya existido ura pretansión del actor cantra el pretor o el Chancellar para el otorgamiento correspondiente dela octio o del writ, y asi poder iriciar formalmente el proceso. Luego de la conselidación de los writs aquello que hablan sida reconocidos podian ser denegados y además se podian crear nusvos. Debe rocondarse además que a partir de 1295 ya no fue necesaria la participación del parlamento $\mathrm{y}$ se podisa incluso modificar ajuellos writs reconocidos, ${ }^{\text {to }}$ Las diferencha encre ambes es en algunos puntos bastante evidente.

c) Mientras on al procesa formulario clásico para garantizar una ockio, el pretor debia decidir otargando razbit al demandante en base a la formalo y al demandado en su caso modante la exceptio, al writ se otergaba bastando las alegaciones que haya efoctuado el demandante. "

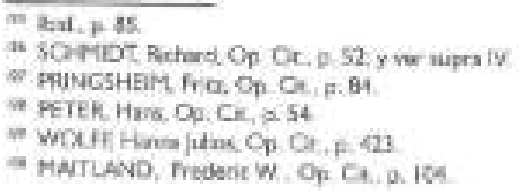


De esta manera no existe correspondencia entre el concepto de fornula (que suponia una primera audiencia con el pretor') y el writ."

d) Así y con estos pardelos que perritin fijar coincidencias y oblerenciss puede sostenerse con coxrección que, tasto en el erdenamiento juridico inglés como en al derecho romano clasico la relacion entre derecho maccrial y formal era evidente e inescindibie. En anbos es posble sostener que la inicad procesal-sustantiva era la bose sobre la que se estructuraban. El erderamiento juridico macerial era organizado y conesbido en base a los mecaniemos de tutela de dercekos que para se resguardo la autoridad crababa o roconoch. El desconocimianto de una octio o writ implicaba b denagaoón de tutela por parte del órgano que desempeńaba función jurisdiceional, impicaba el desconocimiento del derocho que se imocaba ${ }^{\text {in }}$

8) Ello fue combinado con la organización de förmulas receptadas algunas dei derecho romeno medianke los edictiv octionis. De esta maners, el demandante hacia valer su pretensión censistente en alegaciones de derecho mediante un uscrito de demanda, lo que condíjo en la práctuca a una simriltud en las formas y requisicoa dol tibelo (infuencia romana) que consenia una alegaciones y petición de derecho (elemento germano). El sistema de fómulas germanoteutonas con su sistoma de prueba formal era conocido por los angjosajones y fue ol aplicado por los operadores juridicos en Inglecerra. ${ }^{\text {iJ }}$

1) Un desarrollo muy posterior en el norte de ltala dio hugs al surgatiento de a nueva conceptión del dericho mediante el sistema de lus acciones quo en realidad poco infiujó en el sstema inglés. Cronolbgicamente el sisterna inglis ya a partir de mediados del siglo XII se habia conformado con los writs. Paulatinamerte el siscema de la prueba formal foe influenciado par el de la prinba suscantiva que precisaba de una mxacta descripcién de los hechos, lo que fue incorporado dentro del sistema ingles, adquiriendo la alezación de hechos un rol preponderate La exncta descripción de ios supuestos fícticos invocados por ol actor fuenen incorporados er el sisterna ingies a lo largo del tiempo bajo la figura ya existente de alegaciones proceszles de derecha ist Elo se plasmó de la siguiente manora: en in writ no en impnescindible ta correcta descripción juridica de la protensibin, sino que la eacta descr pexon do los hechos se consideró ura alegacián de dorecho cuga correspondencis con el writ escogido tenla por consecuenkia la aceptaciön o rechazo do la demanda. ${ }^{25}$ La exigencia de los edictio oxcianis de una expresa y preciss descripción de la presensión que se hasia valer en el escrito de demanda no tuvo la importancia quo se le dio en el derecho rocnano-itiliço. Si bien las writs como orden debias conconer la exacta descripxión de los hechos no era requasito el adicional edictio octions como si lo ena en el norte de lalia. De all que no resulta sorprendente que para Glanviall el concepto de edictio octionis aun cuando era conocido no revistiera ningún rol. ${ }^{\text {\$o }}$

De io antes desarrollodo puedon enunciarse las siguiences conclusionest en primer lugar los elementes esenciales del sszerna inglós de los wries existian ya en Inglaterra arkes del viglo Xai; en segundo lugar, su desarrallo fue pardelo e inclependiente de las claboraciones doctnrarias del norto de ftala que dieron fundamento al sistema de derecho por acciones que surgio en la segunda mitad del siplo XII, en tercor lugar, es recián luago que pudo haber tenido alguna influencra mediara para ha sistematización del siscema ingles; en cuarto ugar, aun cuando la prais del deracho germano existente en el norte de lealis, llegó a cococerse en lingaterra, aquel no tuvo un rol importante en linghaterra.

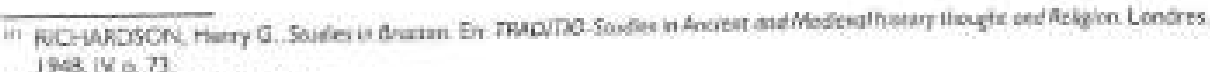
19as, iKa 73

we PETE Ham Os. Citis 5 i

ii KOUMAN Ancrem, Cp. Ct. po $142-143$

it KOLIMAN Andrem Op Or,p. 142

iN PETER Have Os Cri, p. 47

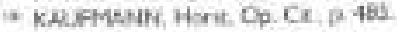


El antiguo Writ-System medieval remite en forma superficial a to esencia del sisterna por acciones dal derecho romane cltako. La influencia de este Cltime, con alguras contadas excepciones no puede ser claramente demostrada' ${ }^{11}$, al menos en relación al surgimiento y desarro lib inicial del sisterra de los wits. " Iquainente el procedimiento seguido por ante los triburiales del Common Low no tuvo pritcticamente ningusa influancin decisva del defecho procesal romano-canónica. Este fue aplicado por la Caurz of Adraralty e influyb al Cammen Low sclo indirectamerte. Si punden enconcrarse una serie de paralelos, que permiten inferir cierta irnlluencia del proceso romano-canónico, entre este y el proceso de Equity, El B.Wl of complaint y el libelo de demanda funcionan en ambos sistemas de ha misma manera: contionan alegación de la controversis en base a los hechos que serviraln luego de fundarnenta para la sentancia de mérito. En ambos casos para acceder a la erapa probatoria se exigia la oposición del demandado respecto a las alegaciones dol actor, in Esto en forma contraria el sistema exstente en el procese del Camman Low, donde las partes debiar arribor at un acuerdo sobre los purtos contradieterios.

La alegaciones comtradicterias de las partes ance la Chancery que permitian determinar los puntos relevantes de prucba es posible encontrarlas también an el procevo romano-canónica. ${ }^{1 *}$ holuse las reformas postenores dol procese de Equity en la odad modera tienen raices en el procese romano-canónico. Los interrogotories se asemejan a las Positionen del proceso romano-cand́nico. En ambos casos se hacia reforencia puntos concretos respocto de los cuales la contraparte debia responder en forma conereata. Finalmente en ambos sistemas regia el principle de la escrituralidad Bill of complant y Arswer debían ser escritos de la misma forma que lo ver en el proceso romano. canórico el libelo de demsoda y de Exceptionen. it

La causa fundamental de la influencia del proceso romano canónice sobre el proceso de Equaty se manifestó on el hecho de que la minyoria de los Ouncellars hacra el siglo XVI recibieron la formación por parte de dérigos sobre el derocho romano-canónico. ${ }^{\text {(4) }}$ Una clara manifostación de eso es que les Chancellors ejercerlan su poder jurisdiccional como "judges af reasan and consciente"the la que implicaba estar sometido a principios tocalmente diferentes de los existentes en el Comman Low. Sin embargo, la jurisprudencia de equidad asumió solo un cardeter de complemento a la del Common Low siendo nocesariamente influenciada a lo largo del tiempo por peincipios, conceptos y estructuras formales propass del Commos Law. ${ }^{144}$ Es por ello qua incluso con este antecedente del procedirviento de oquidad no es posiblo hablar de una racopeión del proceso romano-canónico, siende que el procedimiento del Common Law terminó opacando y finalmente influenciando a aquel en ingliverra. 14

\section{CONCLUSIONES}

Hasta dónda sa conoce, en el feriodo do los anglosajones no es posibis demarcar la exostancia de us proceso chil an Inglaterra, sino más bien de un sistera juridico donde la pretensiones privadas (no diferenciadas de las perales) se efectivizaban haciéndolas valer atribuyendo responsabilidad al demsndado poriendo en él la carga de la prueba. El procedimisnto ere extremadarnente formalista.

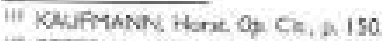

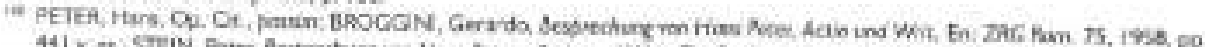

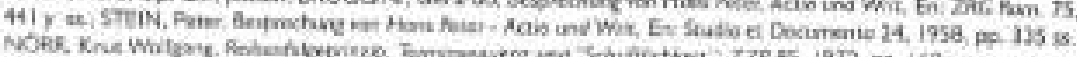

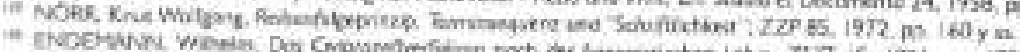

Chasicher C. Op Cr, po. 753,77 .

th BNGER, john H, Op. Cl. D. IIA.

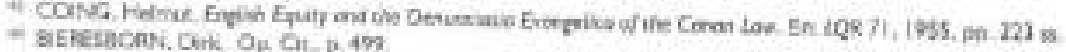

atom

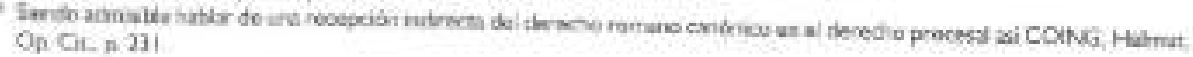


y el detalle del uso de deterrrirudes términos en forma exacta determinads que se ganara o perdiera un proceso. La dependencia de las formas, en azzuno casos como on la prueba, perfectamente tasadas y preestablecidas en su valor con criterios no racionales, sho ritulisticos, sujetaban al derecho imocado en deflnitiva a su suerte procedimental.

Es a partir del siglo XIII que se desarrola en Ingiatorra con al procedimiento de los writ una nueva visión del sistema jurítico. al derecho como un sistema procesal conformado par las distintas fórmulas que permitian solicita la tuteka juriscliceional de los derechos. S. existia el correspondiente writ para el resguardo de un derecho, este recibla turpla jurisdiccional (No writ, no right). La correcta elección dol writ tenia intima vinculación con los presupuestos materiales y procesales de las pretersiones. En efecto el derecho materal era impensable y mucho manos conceptualmente separable del derocho procesal. Mucho mas aun, este útimo era el presupuesto para la existencis del primero. Las consecuencias negativas del formalismo riguroso de les writs no tardaran en manifestarse. La producción, reproducción y modificación de los distintos uvies a los efecros de contemplar distintas situaciones en las cuales se requeris h protección judicial no logró impedir el surgimiento de lagunas. De esta forma habian muchos sipuestos de hecho respecto de las cuales o no existia el respectivo writ, o el que mas se asernejaba terminaba por ser desechado. Este fonómeno del excesivo formalismo en la exigencia de los writs en las cortes del Comman Law da lugar al surgirniento del procedimienso fundado en equidad (Equity).

Si bien es llarnativa la simîtud con la actividad cada vez mis fexible del preter en Roma para otorgar otres medias de tutela de derechos diferentes de una actio coma podia ser un interdicto. Con el sistema de oquidad no solo se flexibiliza el mecanismo de acceso a la tutela judicial, sino que además se desarnolisn reglas procesales que tienden precisamente a superar of ritualismo en el cual habia caido el Common Law. Ambos coexistieron pero serpre tuvo mayor importancia y aplicación personal y muterial el sissema del Comman Low. El procedimiento de equidad no tardó mucho tiempo en integrarse tambión de rigidez y formalismo. Ambos no fueron codificados, se fundaron en la costumbre, practica tribunalicia y en el sistema del precedente. La influencia del derecho romanoirálico y ramano-canónico no fue solo mediata sino cronológicamento posterior al surgimiento de un sistema ya consolidado. Las similitudes de la actio-farmuloe con el right-writ son varias, pero con una independencis y falta de interdependencia que permiten con corrección describir en realidad institutos paralefos similares $y$ no derivades. 